\title{
HUBUNGAN PENGETAHUAN DENGAN PENGGUNAAN ALAT PELINDUNG DIRI PADA PEKERJA INDUSTRI BATU BATA
}

\author{
Rahmiati ${ }^{1}$, Syarifah Nora Andriaty ${ }^{2}$, Andri $^{3}$ \\ ${ }^{1}$ Mahasiswa Kedokteran Umum, Fakultas Kedokteran, Universitas Abulyatama \\ ${ }^{2}$ Dosen Fakultas Kedokteran, Universitas Abulyatama \\ ${ }^{3}$ Dosen Fakultas Kedokteran, Universitas Abulyatama
}

\begin{abstract}
Knowledge Relationship with The Use of Personal Protective Equipment in Brick Industry Workers. Occupational Health and Safety (K3) is a way to protect workers from occupational accidents and occupational diseases. The final stage in the prevention of Equipment (PPE). Occupational accidents and occupational diseases can also occur during the processing of bricks caused by soil which contains nematodes, burning fumes and dust as a result of incomplete combustion. This study aims to determine the relationship between knowledge to the use of PPE in the brick industry workers in Village Lamseunong Sub-district Baitussalam Districts Aceh Besar. The study design was crosssectional survey conducted in 62 respondents were taken with total sampling technique. Collecting data in this study was conducted in 20 February 2019. The use of PPE was measured through observation while knowledge through interviews using a questionnaire. Results of statistical test by Chi-Squre on CI 95\% AND $a=0,05$ for the variable knowledge obtained $p$ value of 0,02 . The clonclusion of this research there is a relationship between knowledge to the use of PPE in the brick industry workers in Village Lamseunong Sub-district Baitussalam Districts Aceh Besar.
\end{abstract}

Keywords: Occupational Health Safety, Brick industry.

\begin{abstract}
Abstrak: Hubungan Pengetahuan dengan Penggunaan Alat Pelindung Diri pada Pekerja Industri Batu Bata. Pelaksanaan Keselamatan Dan Kesehatan Kerja (K3) merupakan suatu cara untuk melindungi pekerja dari kecelakaan kerja dan penyakit akibat kerja. Tahap akhir dalam pencegahan kecelakaan kerja dan penyakit akibat kerja yaitu dengan penggunaan Alat Pelindung Diri (APD). Kecelakaan kerja dan penyakit akibat kerja juga dapat terjadi pada saat pengolahan batu bata yang diakibatkan oleh tanah yang banyak mengandung nematode, asap pembakaran dan debu akibat pembakaran yang tidak sempurna. Penelitian ini bertujuan untuk mengetahui hubungan antara pengetahuan dengan penggunaan APD pada pekerja industri batu bata di Dusun Lamseunong Kecamatan Baitussalam Kabupaten Aceh Besar. Desain penelitian ini adalah crosssectional survey yang dilakukan pada 62 responden yang diambil dengan tehnik total sampling. Pengambilan data pada penelitian ini dilakukan pada tanggal 20 Februari 2019. Penggunaan APD diukur melalui observasi sedangkan pengetahuan melalui wawancara dengan kuesioner. Hasil uji statistic dengan Chi-Squre pada CI 95\% dan $a=0,05$ untuk variabel pengetahuan didapatkan $p$ value 0,02 . Kesimpulan pada penelitian ini terdapat hubungan antara pengetahuan dengan penggunaan APD pada pekerja industri batu bata di Dusun LamseunongKecamatan Baitussalam Kabupaten Aceh Besar.
\end{abstract}

Kata Kunci:Kesehatan Keselamatan Kerja, industri batubata.

\section{PENDAHULUAN}

Pesatnya pembangunan di negara berkembang, ditandai dengan pembangunan industri untuk memenuhi kebutuhan penduduk yang semakin meningkat. Satu diantara industri yang berperan penting yaitu industri batu bata yang merupakan material untuk membangun sebuah bangunan. Kemajuan industri yang pesat dapat 
menimbulkan dampak negatif bagi pekerja apabila tidak diiringi dengan perhatian terhadap kesehatan dan keselamatan kerja yang ditunjang dengan pengembangan Alat Pelindung Diri (APD) sesuai faktor resiko kerja (Odland, 2013).

Indonesia termasuk Negara dengan kecelakaan dan penyakit kerja tertinggi di dunia. Tahun 2013 Indonesia menempati peringkat kedua dunia tertinggi (Gunawan dan Mudayana, 2016).Keselamatan dan Kesehatan Kerja (K3) merupakan suatu upaya untuk menjamin keutuhan dan kesempatan baik jasmani maupun rohani. K3 diharapkan dapat memberikan pekerjaan yang nyaman dan aman bagi para pekerja agar terhindar dari kecelakaan kerja. Peraturan tentang pengadaan K3 Menteri Tenaga Kerja RI No. Per 05/MEN/1996 tentang sistem manajemen keselamatan dan kesehatan kerja. Langkah dalam menjaga kesehatan dan keselamatan kerja merupakan manejemen dan teknis yang baik, langkah selanjutnya adalah menggunakan APD yang baik, benar dan sesuai dengan kebutuhan kerja (Delfa, 2016).

Alat pelindung diri adalah alat yang mampu melindungi seseorang saat bekerja dan menimalkan terjadinya paparan zat berbahaya saat berada ditempat kerja. Perusahaan harus menyediakan APD untuk pekerja dan harus memenuhi Standar Negara Indonesia (SNI). Jenis APD sesuai standar menurut peraturan Menteri Tenaga Kerja dan Transmigrasi Republik Indonesia Nomor PER.08/MEN/VII/2010 tentang APD: Alat pelindung kaki, alat pelindung pernafasan, alat pelindung tangan, alat pelindung mata, dan pakaian pelindung (Menteri Tenaga Kerja dan Transmigrasi, 2016).Pengetahuan K3 berpengaruh terhadap penggunaan APD yang baik dan benar bagi pekerja. Pengetahuan sendiri dapat ditingkatkan

dengan cara memberikan penyuluhan kepada pekerja dan menempelkan poster poster tentang penggunaan APD (Khairudin dan Mudjiman,
2014).Terdapat hubungan yang signifikan antara pengetahuan dengan penerapan $\mathrm{K} 3$ dalam penggunaan APD sehingga dapat mencegah resiko kecelakaan kerja dan penyakit akibat kerja (Huda dan Hastuti, 2013). Industri batu bata merupakan usaha yang memproduksi bahan dasar bangunan yang sering digunakan. Pembentukan batu bata melalui beberapa tahap dan menggunakan alat yang telah ditentukan oleh SNI S-04-1989-F atau SII-0021-78 (Munandar, et al., 2014) Penyakit yang ditimbulkan akibat kerja di indutri batu bata yaitu infeksi cacing tambang, infeksi salauran nafas, konjungtivitis dan katarak. Kecelakaan akibat kerja di industri batu bata yaitu tertimpa benda berat, tertusuk benda tajam, terkena cairan panas dan pajanan api (Rinawati, et al., 2016).

Berdasarkan survey awal yang dilakukan pada bulan November 2018 menunjukan 2 dari 8 pekerja industri batu bata yang sering berhubungan dengan tanah dan paparan asap masih belum menggunakan APD. Pada puskesmas Darussalam didapatkan jumlah kunjungan pasien pada bulan November-Desember didapatkan jumlah penderita Infesi Pernafasan Atas (ISPA) 116 orang, Katarak 8 orang, Konjungtivitis 34 orang, dan Infeksi cacing tambang 5 orang yang merupakan pekerja industri batu bata. Maka peneliti merasa tertarik untuk melakukan penelitian mengenai hubungan pengetahuan dengan penggunan APD pada pekerja industri batu bata di Dusun Lamseunong Kecamatan Baitussalam Kabupaten

Aceh Besar.

Hipotesis dalam studi ini yaitu (Ho) jika tidak terdapat hubungan antara pengetahuan dengan penggunaan alat pelindung diri pada pekerja industri batu bata, ( $\mathrm{Ha}$ ) jika terdapat hubungan antara pengetahuan dengan penggunaan alat pelindung diri pada pekerja industri batu bata. Adapun rumusan masalahnya, apakah terdapat adanya hubungan pengetahuan dengan penggunaan APD pada pekerja industri batu bata. 
Penelitian ini bertujuan untuk mengetahui hubungan pengetahuan dengan penggunaan APD pada pekerja industri batu bata. Untuk mengetahui tingkat pengetahuan pekerja industri batu bata dan untuk mengetahui persentase pemakaian APD pada pekerja industri batu bata. Penelitian ini diharapkan dapat memberikan informasi tentang pengetahuan terhadap penggunaan APD.

\section{METODE}

Peneitian ini menggunakan pendekatan kuantitatif obsevasional dengan desain crossectional survey. Variabel independent meliputi pengetahuan, sedangkan variabel dependent yaitu penggunaan alat pelindung diri. Populasi dalam penelitian seluruh pekerja industri batu bata yang berjumlah 62 orang. Tehnik pengambilan sampel menggunakan total sampling. Lokasi penelitian dilakukan di industri batu bata Dusun Lamseunong
Kecamatan Baitussalam Kabupaten Aceh Besar Provinsi Aceh. Penelitian dilakukan dari tanggal 20 Februari sampai 21 Februari 2019. Penelitian ini menggunakan data primer yang diperoleh melalui obsevasi dan wawancara dengan kuesioner. Data dianalisis mengunakan analisis univariat dan bivariate, analisis univariat untuk melihat distribusi dan frekuensi variabel dependent dan independent, dan analisis bivariate untuk mengetahui hubungan antara variabel pengetahuan dan variabel penggunaan alat pelindung diri yang dianalisis dengan uji ChiSqure $\left(X^{2}\right)$ dengan nilai $a=0,05$, dengan ketentuan yang berlaku yaitu bila $p$ value $\leq \mathrm{a}(0,05)$, maka ada hubungan yang bermakna antara variabel independent dan variabel dependent.Bila $p$ value $\geq a(0,05)$ maka tidak ada hubungan yang bermakna antara varibel independent dan variabel dependent.

\section{HASIL}

Tabel 1. sDistribusi Frekuensi Jenis APD yang digunakanPekerja Industri Batu Bata di Dusun Lamseunong Kecamatan Baitussalam Kabupaten Aceh Besar.

\begin{tabular}{lllll}
\hline $\begin{array}{l}\text { Jenis APD } \\
\text { yang digunakan }\end{array}$ & $\mathrm{n}$ & $\%$ & $\mathrm{n}$ & $\%$ \\
\hline $\begin{array}{l}\text { Pelindung } \\
\text { Mata }\end{array}$ & 1 & 2 & 61 & 98 \\
$\begin{array}{l}\text { Pelindung } \\
\text { Pernafasan }\end{array}$ & 5 & 8 & 57 & 92 \\
$\begin{array}{l}\text { Pelindung } \\
\text { Tangan }\end{array}$ & 50 & 81 & 12 & 19 \\
Pelindung Kaki & 60 & 58 & 26 & 42 \\
\hline
\end{tabular}

Hasil observasi tidak dijumpai pekerja yang menggunakan pakaian pelindung saat bekerja, $98 \%$ pekerja tidak menggunakan pelindung mata, $92 \%$ pekerja tidak menggunakan pelindung organ pernafasan, $19 \%$ pekerja batu bata tidak menggunakan pelindung tangan, dan $42 \%$ pekerja tidak menggunakan pelindung kaki.

Tabel 2. Distribusi Frekuensi Pekerja Batu Bata yang Menggunakan APD di Dusun Lamseunong Kecamatan Baitussalam Kabupaten Aceh Besar

\begin{tabular}{cccc}
\cline { 2 - 3 } Pengetahuan & \multicolumn{2}{c}{ Frekuensi(n) } & Persentase\% \\
\cline { 2 - 4 } Lengkap & 29 & 47 &
\end{tabular}


Berdasarkan Tabel 2 di atas menunjukan bahwa pekerja yang menggunakan APD dengan lengkap

adalah $47 \%$, sedangkan pekerja yang menggunakan APD tidak lengkap adalah $53 \%$.

Tabel 3. Distribusi Frekuensi Pertanyan Pengetahuan

PekerjaIndustri Batu Bata di Dusun Lamseunong

Kecamatan Baitussalam Kabupaten Aceh Besar

\begin{tabular}{|c|c|c|c|c|}
\hline \multirow{2}{*}{ Pengetahuan } & \multicolumn{2}{|c|}{ Baik } & \multicolumn{2}{|c|}{ Tidak Baik } \\
\hline & $\mathrm{n}$ & $\%$ & $\mathrm{n}$ & $\%$ \\
\hline Apakah yang dimaksud dengan APD? & 46 & 74 & 16 & 26 \\
\hline $\begin{array}{l}\text { Menurut anda apakah APDberguna Pada } \\
\text { waktu bekerjadi industri batu bata? }\end{array}$ & 58 & 94 & 4 & 6 \\
\hline $\begin{array}{l}\text { APD apa saja yang harusdigunakan oleh } \\
\text { pekerja industri batu bata saat bekerja? }\end{array}$ & 37 & 60 & 25 & 40 \\
\hline $\begin{array}{l}\text { Apa akibat bila pekerja tidak menggunakan } \\
\text { APD? }\end{array}$ & 48 & 77 & 14 & 23 \\
\hline $\begin{array}{l}\text { Menurut anda kapan APD tersebut mulai } \\
\text { digunakan? }\end{array}$ & 2 & 3 & 60 & 97 \\
\hline
\end{tabular}

Hasil kuesinoer dengan pekerja industri batu bata dari pertanyaan pertanyaan yang diajukan terdapat $74 \%$ pekerja industri batu bata yang mengetahui pengertian APD dan $26 \%$ pekerja tidak mengetahui pengertian APD, 94\% pekerja mengetahui kegunaan APD saat bekerja dan $6 \%$ pekerja tidak mengetahui kegunaan APD saat bekerja, 60\% pekerja mengetahui jenis jenis APD dan $40 \%$ pekerja tidak mengetahui jenis jenis APD yang harus digunakan saat bekerja, $77 \%$ pekerja mengetahui dampak apabila tidak menggunakan APD dan $23 \%$ pekerja tidak mengetahui dampak apabila tidak menggunakan APD saat bekerja, 3\% pekerja mengetahui kapan APD harus digunakan dan $97 \%$ pekerja tidak mengetahui kapan APD harus digunakan.

Tabel 4. Distribusi Frekuensi Tingkat Pengetahuan Pekerja Industri Batu Bata di Dusun Lamseunong Kecamatan Baitussalam Kabupaten Aceh Besar

\begin{tabular}{cccc}
\hline Pengetahuan & Frekuensi(n) & Persentase $\%$ \\
\hline Baik $\begin{array}{c}33 \\
\text { Tidak baik }\end{array} 29$ & 53 & 47 \\
Total & 62 & & 100 \\
\hline
\end{tabular}

Berdasarkan Tabel 4. Diatas terlihat bahwa pekerja industri batu bata yang memiliki pengetahuan baik tentang penggunaan APD sebesar
$53 \%$, sedangkan pekerja industri batu bata yang memiliki pengetahuan kurang baik tentang penggunaan APD sebesar $47 \%$. 
Tabel 5. Hubungan Pengetahuan Dengan Penggunaan APD Pada Pekerja Industri Batu Bata di Dusun Lamseunong Kecamatan Baitussalam Kabupaten Aceh Besar

\begin{tabular}{lcccccccccc}
\hline \multicolumn{1}{l}{ Penggunaan APD } \\
\hline \multicolumn{1}{l}{ Pengetahuan } & Lengkap & \multicolumn{1}{l}{ Tidak Lengkap } & Total & $P$ & $R P$ \\
\hline $\mathrm{n}$ & $\%$ & $\mathrm{n}$ & $\%$ & $\mathrm{n}$ & $\%$ & Value \\
\hline Baik & 20 & 66 & 1 & 34 & 33 & 100 & 0,02 & 1,93 \\
Tidak Baik & 9 & 31 & 20 & 69 & 29 & 100 & & \\
\hline
\end{tabular}

Berdasarkan Tabel 5. Diatas didapatkan bahwa pekerja industri batu bata yang berpengetahuan baik dan menggunkan APD dengan lengkap sebesar $66 \%$ dan yang berpengetahuan baik dan tidak lengkap menggunakan APD sebesar $33 \%, 31 \%$ pekerja industri yang berpengetahuan tidak baik dan menggunakan APD dengan lengkap sebesar $31 \%$ dan yang berpengetahuan tidak baik dan tidak lengkap menggunakan APD sebesar $29 \%$.

\section{PEMBAHASAN}

Pengetahuan

tentang penggunaan APD merupakan satu diantara aspek penting sebagai pemahaman terhadap pentingnya peran serta pengawas dan pemilik perusahaan dalam penggunaan APD (Raodhah dan Gemely, 2014). Penggunaan APD yang baik dan benar didasarkan oleh pengetahuan pekerja tentang APD (Hirliansyah, 2013; Wijayanti, et al., 2016). Apabila pekerja memiliki pengetahuan yang kurang terhadap potensi atau sumber bahaya yang ada di lingkungan kerjanya, maka pekerja tersebut akan cenderung membuat suatu keputusan yang salah (Soedarto, 2013). Pengetahuan bukan satu satu nya faktor, faktor lainnya seperti ketersediaan APD di tempat kerja (Soedarto, 2013; Notoadmojo, 1989). Ketersediaan APD merupakan faktor pendukung dalam kepatuhan menggunakan APD untuk mencegah terjadinya kecelakaan dan resiko kerja yang terjadi di perusahaan, jika perusahaan tidak menyediakan APD berarti perusahaan telah membahayakan pekerjanya dari resiko kecelakaan dan penyakit yang akan timbul di lingkungan kerja (Kurnawidjaja, 2016).

Pengetahuan merupakan salah satu domain yang dapat membentuk perilaku seseorang (Handayani dan Suryani, 2014). Menurut pandangan dari sunaryo 2014 suatu perliaku yang didasari pengetahuan akan lebih bertahan lama dari pada perilaku yang tidak didasari oleh pengetahuan (Notoadmojo, 2013; Saikh dan Yousuf, 2014).

Pengetahuan pekerja industri batu bata masih sangat minim. Hasil pengukuran hubungan pengetahuan dengan penggunaan APD yang telah dilakukan dan dianalisis dengan menggunakan uji statistik Chi-Squre pada interval kepercayaan 95\% dengan $\mathrm{a}=0,05$ menunjukkan adanya hubungan antara pengetahuan dengan penggunaan alat pelindung diri pada pekerja industri batu bata dengan nilai $p$ value 0,02 . Penelitian ini juga sejalan dengan penelitian 
Wibowo, adanya hubungan yang signifikan antara pengetahuan dengan penggunaan alat pelindung diri pada pekerja pengolahan emas di Bogor dengan nilai $p$ value 0,000 (Husaini, et al., 2016). Bukhari menyatakan adanya hubungan yang signifikan antara pengetahuan dengan penggunaan alat pelindung diri pada karyawan dengan nilai $p$ value 0,033 (Oktaviani dan Prasasti, 2015).Pernyataan Wahyuni adanya hubungan yang signifikan antara pengetahuan dengan penggunaan alat pelindung diri pada karyawan dengan nilai $p$ value 0,029 (Alayyannur, 2017).

Penelitian ini juga selaras dengan penelitian Banibrata adanya hubungan yang signifikan antara pengetahuan dengan penggunaan alat pelindung diri pada pekerja unit Amoniak Produksi dengan nilai $p$ value 0,000 (Banibrata, 2014).Repi menyatakan adanya hubungan yang signifikan antara pengetahuan dengan penggunaan Alat Pelindung Diri pada pekerja bagian Weaving dengan nilai $p$ value 0,000 (Repi, 2015).Pernyataan Wahyuni adanya hubungan yang signifikan antara pengetahuan dengan penggunaan Alat Pelindung Diri pada pekerja bagian winding dengan nilai $p$ value $0,001 .{ }^{25} \mathrm{Hasil} \quad$ Penelitian ini menunjukan semakin tinggi tingkat pengetahuan seseorang tentang APD maka akan semakin baik perilaku terhadap penggunaan APD (Sutrisno dan Wisnu, 2014).Keterbatasan pada penelitian ini tidak semua responden hadir dan tidak semua responden setuju diwawancarai.

\section{KESIMPULAN}

Kesimpulan dari penelitian ini didapatkan jumlah pekerja industri batu bata di Dusun Lamseunong yang berpengetahuan baik adalah 33 orang atau $53 \%$, sedangkan yang berpengetahuan kurang baik adalah 29 orang atau 47\%, dan jumlah pekerja industri batu bata yang menggunakan Alat Pelindung Diri yang lengkap adalah 29 orang atau
$47 \%$, sedangkan yang menggunakan Alat Pelindung Diri tidak lengkap adalah 33 orang atau 53\%, Terdapat hubungan antara pengetahuan dengan penggunaan Alat Pelindung Diri pada pekerja industri batu bata di Dusun Lamseunong Kecamatan Baitussalam Kabupaten Aceh Besar.

\section{SARAN}

Berdasarkan hasil dan kesimpulan penelitian diatas, maka peneliti mencoba memberikan saran saran ataupun masukan, yakni sebagai berikut: Bagi peneliti diharapkan penelitian ini menjadi bahan bacaan dan acuan serta penyempurnaan penelitian selanjutnya untuk menambah wawasan serta ilmu pengetahuan bagi peneliti, sehingga dapat mempertimbangkan variabel lain. Bagi Dinas Kesehatan hendaknya mengadakan penyuluhan tentang pentingnya penggunaan APD untuk meningkatkan pengetahuan pekerja industri batu bata. Bagi perusahaan hendaknya menyediakan APD yang lengkap bagi pekerja industri batu bata dan memberikan sanksi kepada pekerja apabila tidak menggunakan Alat Pelindung Diri secara rutin selama bekerja. Bagi tenaga kerja diharapkan dapat menggunakan atau memakai APD secara rutin dan memperhatikan keselamatan bagi dirinya sendiri ataupun lingkungan sekitar agar terhindar dari kecelakaan kerja ataupun faktor resiko yang akan terjadi.

\section{DAFTAR PUSTAKA}

Odland, AA. (2013).Hubungan Kepatuhan Peggunaan APD dengan Tingkat Angka Kecelakaan Kerja. J Internasional Kesehatan Circumpolar. 27 (2): 72-81.

Gunawan dan Mudayana.
(2016). Hubungan
AntaraPengetahuan, Sikap


dan Motivasi Dengan Perilaku Penggunaan Alat Pelindung Diri Pada Pekerja Bagian Produksi. J of Public Health. 5 (4): 80-85.

Delfa.Pusat Data dan Informasi Kementerian Republik Indonesia. (2016). [Internet]. Diakses pada 22 Mei 2015, dari: www.depkes.go.id.

Transmigrasi. Peraturan Menteri Tenaga Kerja dan Transmigrasi Republik Indonesia. (2010). [Internet]. Diakses pada 9 Maret 2010, dari:

https://aswinsh.wordpress.co m.

Khairudin dan Mudjiman. 2014.Studi Aksesibilitas Terhadap Bahan Baku dan Pemasaran Batu Bata Serta Karakteristik Penghasil Batu Bata. J of Public Health. 16 (8): 91-105.

Huda dan Hastuti. (2013).Pengaruh temperatur pembakaran dan penambahan abu terhadap kualitas batu bata. $J$ of Neutrino. 4 (2): 142-152.

Munandar, Agusti, dan Hakam. (2014).Pengaruh

Keselamatan, Kesehatan Keraja (K3) dan Insentif Terhadap Motivasi dan Kinerja Karyawan. J Administrasi Bisnis. 1 (9): 1-9.

Rinawati, Nur Widowati. (2016). Pengaruh Tingkat pengetahuan Terhadap Pelaksanaan Pemakaian Alat Pelindung Diri. J of Industrial Hygiene and Occupational Health. 1 (5): 53-55.

Raodhah dan Gemely.(2014). FaktorFaktor Yang Berhubungan Dengan Penggunaan Alat Pelindung Diri Pada Karyawan Bagian Packer. J Kesehatan Andalas. 5 (2): 437-449.

Hirliansyah. (2013).Pengawasn Oleh Badan Pengawas Lingkungan Hidup Kota Bndar Lampung Terhadap Pengelolaan Limbah Hasil Pembakaran Batu Bara
Bagi Industri. J Administrasi Negara. 3 (13): 133-135.

Wijayanti, Raharjo, dan Liana. (2016).Hubungan

Pengetahuan, Sikap dan Tindakan Penggunaaan Alat Pelindung Diri Terhadap Keluhan Gangguan Kulit pada Petugas Sampah TPA. [Internet]. Diakses pada 4 April 2016, dari: https://media.neliti.com.

Soedarto. (2013). Buku Ajar Parasitologi Kedokteran. Jakarta, EGC.

Notoatmodjo. (1989). Buku Ajar Promosi Kesehatan. Jakarta, PT Rineka Cipta.

Kementerian Kesehatan RI.Permenkes No 1 Tahun 1970Tentang Keselamatan dan Kesehatan Kerja. Jakarta. Kementerian Kesehatan 1970.

Kurnawidjaja. (2016). Situasi Strategi Promosi Kesehatan Di Vico Indonesia. $J$ PROMKES. 2 (5): 93-104.

Handayani dan Suryani. (2014).Hubungan Antara Penggunaan Alat Pelindung Kerja Pada Pekerja Bagian Rustic Di PT Borneo. J Kesehatan Masyarakat. 2 (6): 208-217.

Oktavia. 2014.Hubungan Antara Penggunaan Alat Pelindung Kerja Pada Pekerja Bagian Pengelasan. J Kesehatan Masyarakat. 5 (9): 103-120.

Notoatmodjo.(2013). Pendidikan dan Perilaku Kesehatan. Jakarta: PT Rineka Cipta.

Shaikh dan Yousuf. (2014). Hubungan Tingkat Pengeahuan dan Pendidikan Terhadap Kepatuhan Penggunan Alat Pelindung Diri; 2014. [Internet]. Diakses pada 7 Mei 2014, dari: https://www.researchgate.net Husaini, Marsetyawan dan Heru. (2016).Koreksi Terhadap Pengukuran Polutan di Udara Unit Perajin Logam dan Dampaknya Terhadap 
Kesehatan. J Buletin Penelitian

Kesehatan. 44 (2): 91-102.

Oktaviani dan Prasasti. (2015). Kualitas Fisik dan Kimia Udara, Karakteristik Pekerja, Serta Keluhan Pernapasan Pada Pekerja Percetakan. J Kesehatan Lingkungan. 8 (2): 195-205.

Alayyannur. 2017.Personal Protective Equipment Helps You Stay Safe and Healthy. [Internet]. Diakses pada 9 April 2017, dari:

https://www.researchgate.net

Banibrata. (2014), Assessment Of Occupational Health Problems and Physiological Stress Among The Brick Field Workers Of West Bengal. J of
Occupational Medicine. 27 (3): 413-425.

Repi. (2015). Kesehatan dan Keselamatan Pekerja Yang Tidak Memakai Peralatan Yang Safety Di Industri Tepung Kelapa. [Internet]. Diakses pada 22 Maret 2015, dari: https://www.academian.edu.

Wahyuni. 2016.Analisis Bahaya dan Penilaian Kebutuhan Alat Pelindung Diri Pada Pekerja Pembuat Batu Bata.J Kesehatan Masyarakat. 10 (1): 22-27.

Sutrisno dan Wisnu. (2014).Analisis Resiko Cemaran Debu (TPS) Akibat Asap Pabrik Terhadap Pekerja dan Masyarakat Sekitar. J Teknik Lingkungan. 5 (7): 1-7. 